\title{
The current treatment-a survey of osteoporotic fracture treatment. Osteoporotic spine fractures: the spine surgeon's perspective
}

\author{
Paul F. Heini
}

Received: 4 June 2004 / Accepted: 26 July 2004/ Published online: 9 September 2004

(C) International Osteoporosis Foundation and National Osteoporosis Foundation 2004

\begin{abstract}
For the spine surgeon the problems of the osteoporotic spine can be a painful simple compression fracture, the persisting instability after a fracture, the silent loss of posture due to progressive collapse of multiple vertebrae, and neurological complications related to an osteoporotic fracture. The use of polymethylmethacrylate (PMMA) for the reinforcement of osteoporotic vertebral bodies has turned out to be extremely efficient. Although the natural course of pain due to vertebral fractures decreases within the first weeks in the majority of patients, there remains a number of them with persistent pain and/or ongoing vertebral collapse. With percutaneous cement injection one can achieve fast and lasting pain reduction in $80 \%$ to $93 \%$ of patients. With multilevel injections it is possible to address the severe osteoporotic spine as a whole where we can halt the ongoing collapse and preserve posture efficiently. Rectification of lordosis can be achieved in fresh fractures with the kyphoplasty technique and, even more efficiently, with the lordoplasty procedure. Kyphosis correction ranges from $8.5^{\circ}$ to $14^{\circ}$, and restoration of vertebral body (VB) height goes up to $90 \%$. When surgical stabilization is required, the combination of PMMA reinforcement and fixation with screws appears the only alternative in order to anchor the implants in the severely osteoporotic bone.
\end{abstract}

Keywords Internal fixation - Kyphoplasty · Lordoplasty · Neurological deficit · Osteoporosis · Spine $\cdot$ Vertebroplasty

P.F. Heini

Department of Orthopaedic Surgery,

Inselspital Bern, Freiburgstrasse, 3010,

Berne, Switzerland

E-mail: paul.heini@insel.ch

Tel: + 41-31-6322111

Fax: +41-31-6323600

\section{Introduction}

The spine is the most common site of osteoporotic fractures [1]. In the USA approximately 700,000 new osteoporotic fractures are seen every year, of which one-third become chronically painful $[2,3]$. The incidence of osteoporotic vertebral body compression fractures (VBCFs) in women older than 50 years is more than ten out 1,000 per year and is three-times higher after the age of $75[3,4$, 5]. Approximately $25 \%$ of women older than 70 years show at least one $\mathrm{VBCF}$, and more than $50 \%$ of women after the age of 80 [6,7]. Osteoporotic compression fractures are a leading cause of disability and morbidity in the elderly $[4,8,9,10,11,12]$. Patients with VBCFs show a higher mortality rate than the general population [13].

Medical treatment with calcium, vitamin D, bisphosphonates, raloxifene, hormone replacement, and parathormone, are highly effective in reducing the fracture risk. However as many as one-third of patients continue to experience pain. Approximately $15 \%$ of individuals continue to sustain fractures, despite therapy. Furthermore, there is a considerable number of nonresponders and non-compliant patients $[4,14,15,16]$.

\section{Clinical problems related to osteoporotic fractures}

For the spine surgeon, the problems related to fractures of the osteoporotic spine can be classified as (a) acute and subacute single-level fractures, (b) fractures with persistent instability, (c) (multiple) fractures with progressive/creeping vertebral collapse and loss of sagittal balance and posture, and (d) vertebral fractures with subsequent spinal stenosis/neural compression (Fig. 1).

Acute/subacute simple compression fractures

Although the majority of simple VBCFs can be treated non-operatively (rest; analgesics; external support) with self-limiting pain for a few days to weeks, approximately one-sixth of sufferers become bedridden 


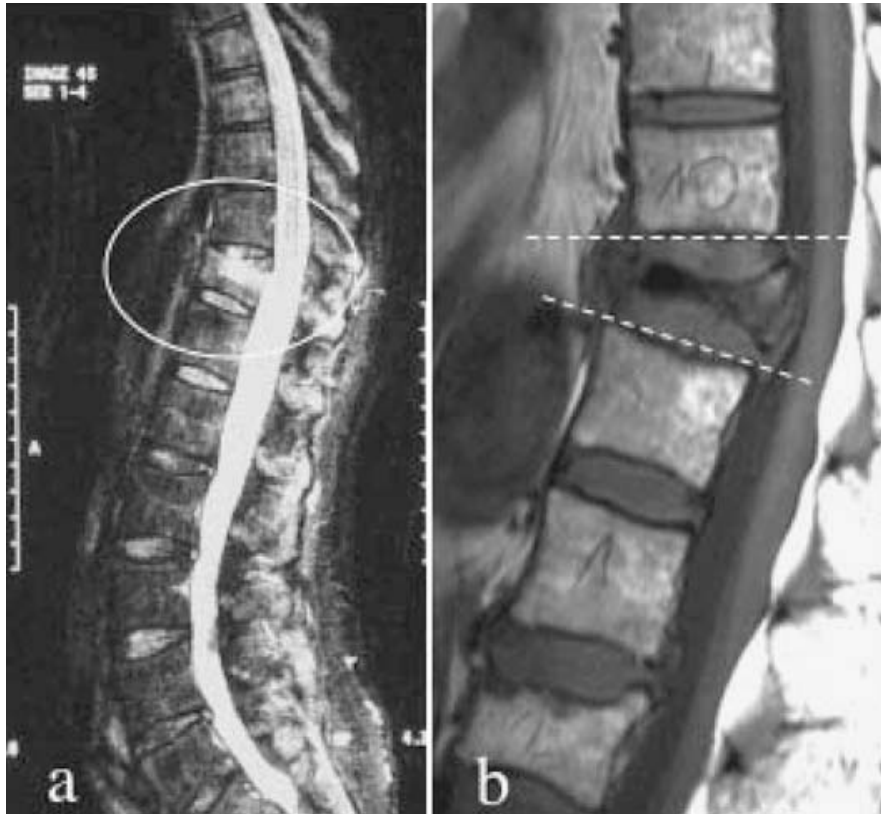

Fig. 1a-d Spectrum of spine problems related to osteoporosis. a Simple compression fracture with ongoing pain 2 months after onset. b Non-union 6 months after fracture of T11. The persisting instability causes pain during change of position. c Fractures of multiple vertebrae are responsible for loss of posture and neck pain in order to compensate for the deformed thoracic spine. d Fracture of $\mathrm{T} 7$ with concomitant spinal canal encroachment and compression of the spinal cord

and need hospital admission [17]. Furthermore, there is a certain percentage of patients that are going to encounter a progressive collapse of the vertebral body (VB) within an undetermined time period and finish with a pronounced deformity of the spine.

The clinical appearance of patients with fresh $\mathrm{VBCF}$ is rather uniform, with sharp localized mechanical back pain in the initial phase. After a while, the breathtakingly sharp pain is relieved, and there remains a local pain that increases under load.

Therapeutic options. With this group of patients, where the initial pain is so severe or the conservative measures are not sufficient, percutaneous cement reinforcement appears to be the treatment of choice. Several clinical studies document its usefulness [18, 19, 20, 21, 22, 23]. In fresh fractures the pain improvement is seen in $93 \%$ of patients [24]. However, in older lesions the treatment can be effective in as many as $80 \%$ of patients $[25,26]$. In our initial series pain improvement, from VAS 7.8 to 2.6 , was seen in $87 \%$ of the patients [20] and remains so for the over 500 patients that we have meanwhile treated. However, up until now there have been no randomized controlled trials performed that compared vertebroplasty with conservative treatment (Fig. 2).

\section{Persisting instability/non-union}

The natural history usually leads to a spontaneous consolidation of the deformed VB, but, in some cases,

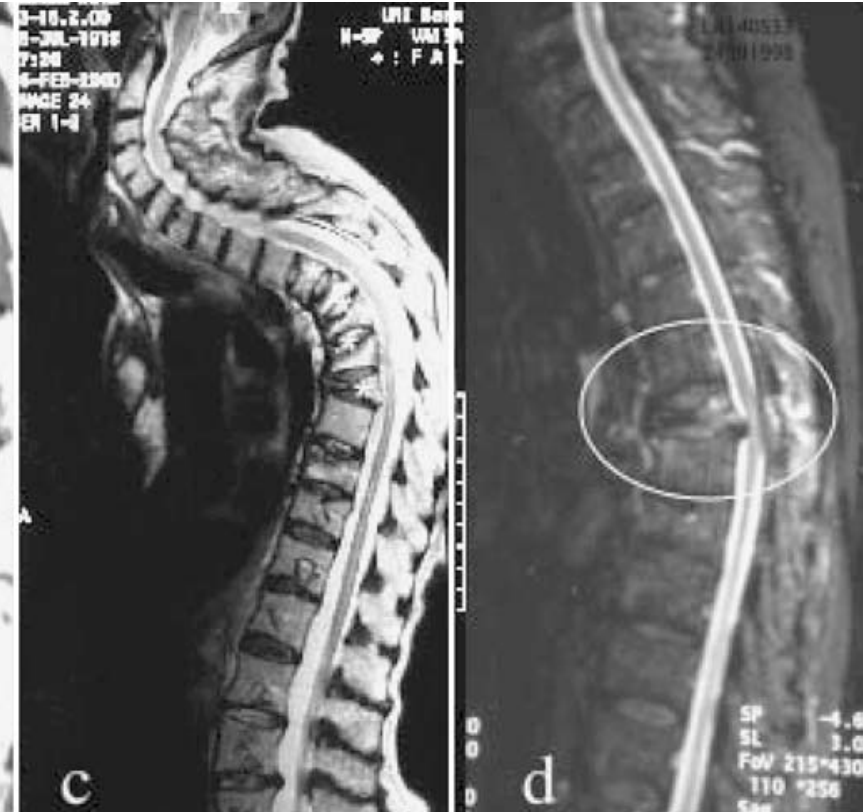

there remains an instability after a fracture, which can be the cause of ongoing pain. This has been described as Kümmell's disease and dynamic mobility (Fig. 3) [27, 28].

Clinical presentation. Patients with a non-union describe a characteristic symptomatology: when they are lying supine they have little or no pain; however, as soon as they get to the upright position they experience an intense local pain that subsides once they are completely upright. During their change of position, the unstable vertebra is loaded and collapses until a new stable situation is reached. This collapse is the cause of this severe pain during the change of position. This instability can best be demonstrated by comparing a lateral view in the standing position with a lateral X-ray in the supine position. Any movement in a fractured vertebra is defined as instability [27, 28].

Therapeutic options. In patients with a non-union the reinforcement can provide stability and pain relief, and, as much as positioning allows, a correction of the deformity can also be achieved [27, 28] (Fig. 3).

Severe osteoporosis with multiple fractures and progressive loss of posture

Another group of patients is that with very severe osteoporosis, where a progressive loss of posture is occurring due to recurrent fractures and ongoing loss of vertebral height. This might occur within a short time period or over years.

The clinical presentation of these patients differs from the first group, as there is a more diffuse backache, and strain over the whole back. Patients find it difficult to stand erect for long periods and have to bend forward because of the increased pain when they try to straighten up. They frequently have a history of steroid intake and 


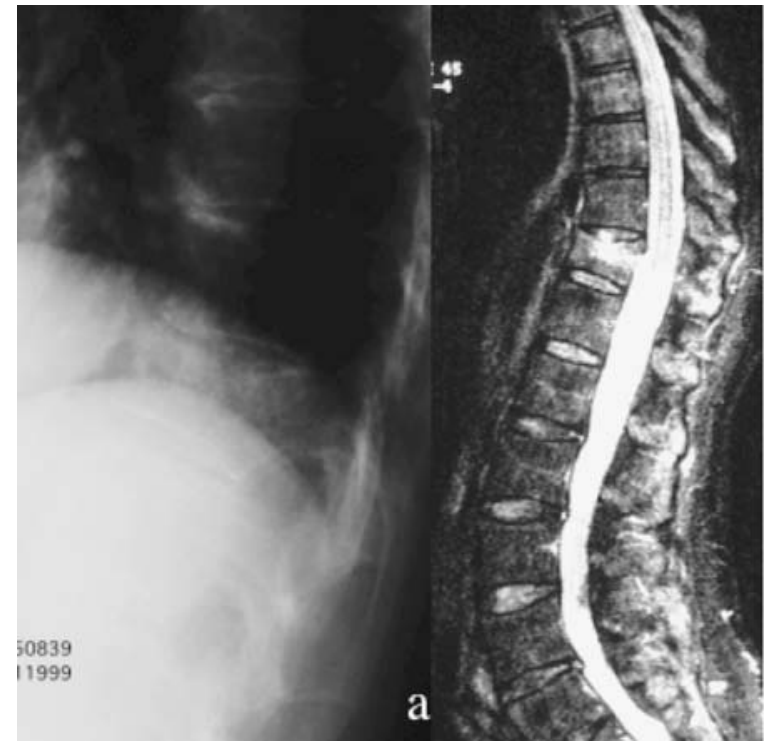

Fig. 2a,b MR images of the spine of a 60-year-old woman with a compression fracture of T11 and ongoing pain for 3 months. The image depicts persisting edema as expression of a still fresh/active fracture pattern (a). Treatment was performed with PMMA injection. Immediate and lasting pain relief was obtained after reinforcement with PMMA (b); FU after 1.5 years. The patient is under medical treatment with bisphosphonates but receives no pain medication

are most often multi-morbid (after transplantation surgery; renal and bowel diseases; long-lasting bed rest). With careful history taking one can learn that there were episodes of pain exacerbation, which most probably represent incidences of new fractures.

Therapeutic options. The treatment of these patients, except for medication for the osteoporosis and administration of analgesics, appears difficult at first glance. The increasing experience with vertebroplasty has let us to approach the osteoporotic spine as a whole. In one

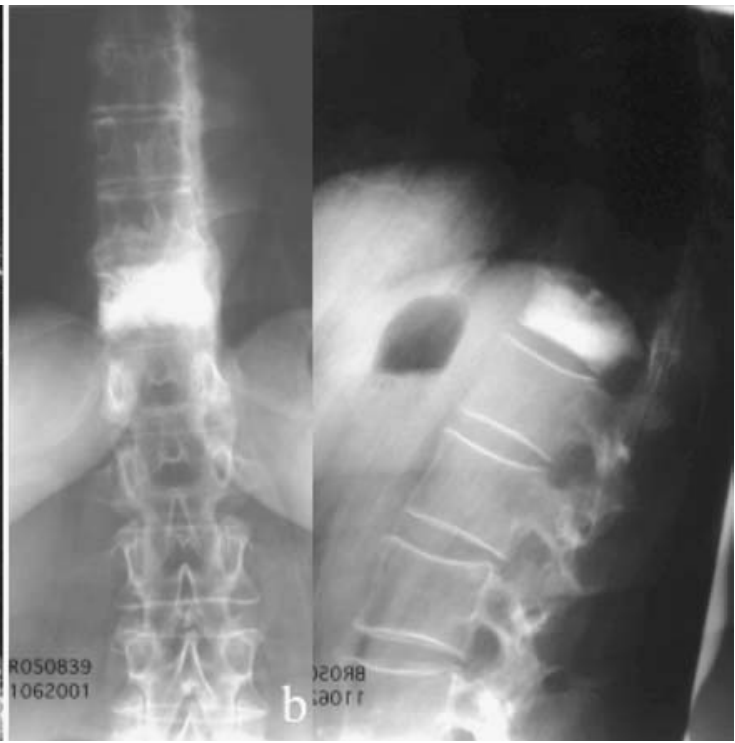

session one can reinforce six levels and, if necessary, add further levels in a second or even third session. In our series of more than 500 treated patients, $30 \%$ had five or more levels injected [29]. The effect for those patients has been an important decrease of pain, which enabled them to stay/stand erect again. The mid-term follow-up over 4 years has shown, furthermore, a halt in the collapse of the treated vertebrae and preserved disc height (Fig. 4).

Osteoporotic fractures with subsequent spinal stenosis and neurological compromise

Cases of fractures with subsequent neural compromise due to a deformity (thoracic kyphosis, Fig. 1d) or instability (lumbar spinal stenosis, Fig. 7) are seen with increasing frequency in the spine surgeon's practice. Displaced fragments may narrow the spinal canal, with
Fig. 3a-c Patient with persisting pain 6 months after a T11 fracture. The pain is severe during change from the supine to the sitting position. The MR image shows a nearly complete collapse of T11 (b) but some degree of spontaneous correction of the kyphosis in comparison with the standing $\mathrm{X}$-ray (a). The patient was treated with a closed reduction maneuver and cement reinforcement. The X-ray 6 months after the procedure shows a satisfactory alignment of the spine, and the patient is without pain (c)
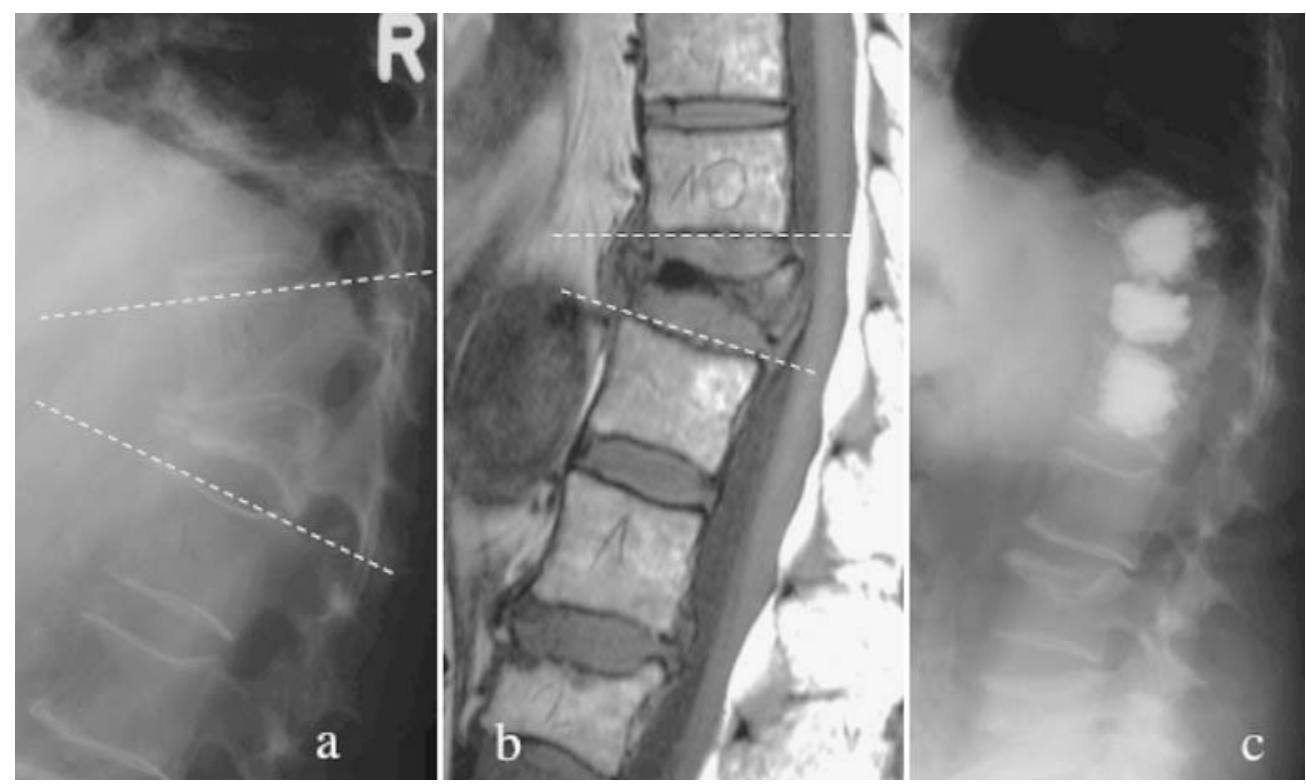

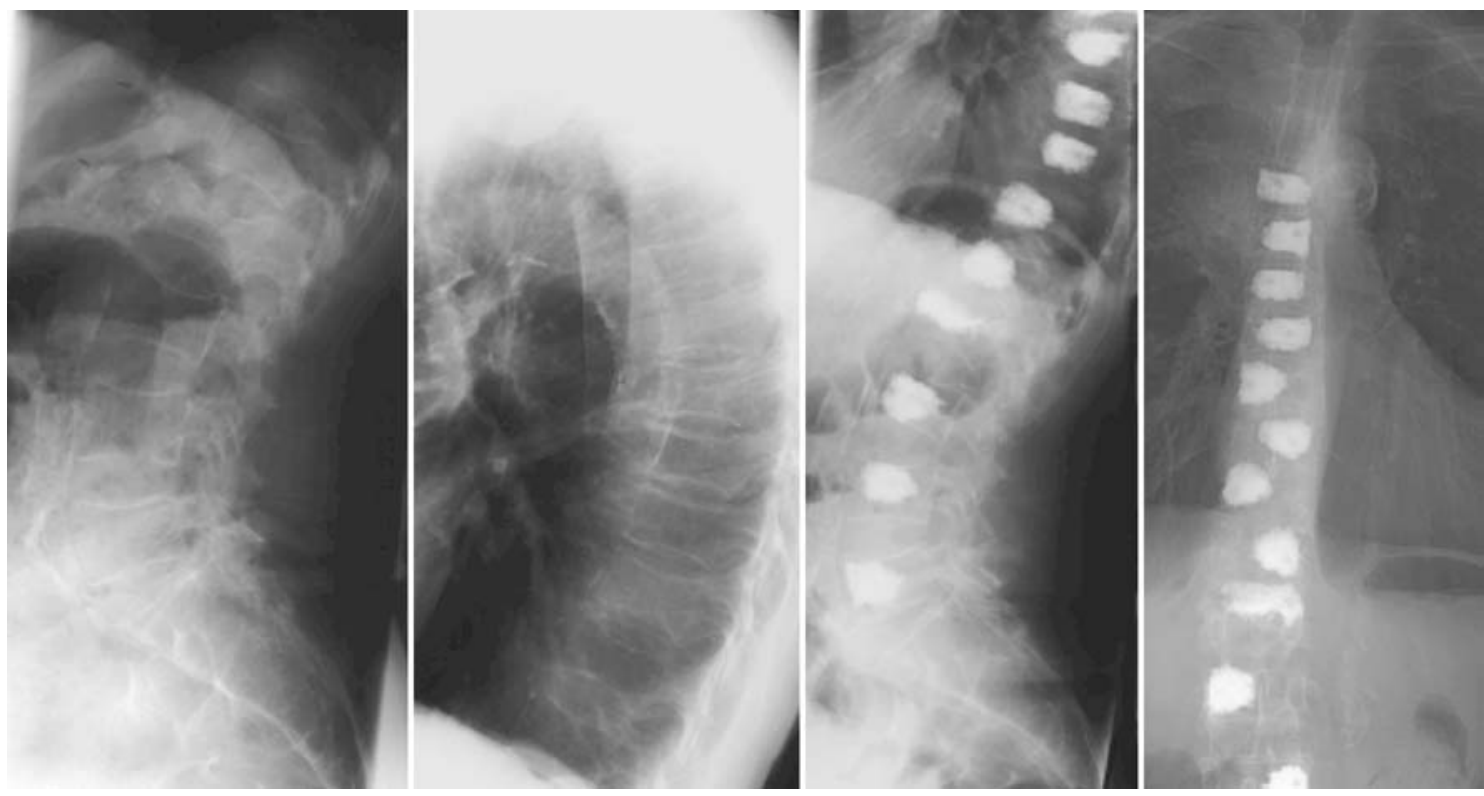

Fig. 4 X-rays of the spine of a 68-year-old woman under steroid medication for years due to a heart transplantation. The patient complained about severe pain episodes and chronic strain in her whole back. She lost $7 \mathrm{~cm}$ of height during a 16-month period. The $\mathrm{X}$-rays show severe osteoporosis with multiple fractures of the lumbar and thoracic spine. She was treated with PMMA injection from T5 to L5 in three sessions of 45 min each. The collapse was halted, and the patient experienced significant relief from her back pain and was able to have a much better posture afterwards

subsequent compression of the spinal cord or nerves. Due to the height loss a foraminal narrowing may lead to nerve root compression. More and more reports are found in the literature about this issue $[30,31,32,33$, 34].

The clinical presentation shows severe local mechanical back pain together with a radiating pain that usually subsides in the supine position. In some cases motor weakness may occur. The X-ray findings show severe deformity, and in an MR image or a myelogram spinal canal encroachment is seen. Lumbar scoliosis may occur due to a fracture and contribute, furthermore, to sagittal dysbalance.

Therapeutic options. Decompression alone is not suitable to address this kind of problem [34, 35]. Any closed measures with cement reinforcement will not relieve symptoms derived from spinal stenosis so long as the collapsed segment cannot be restored (see below). An open procedure, with decompression of the spinal canal and internal fixation and fusion, is usually required. However, the problem of anchoring the implants in the osteoporotic bone, on the one hand, and the risk of new fractures adjacent to the stabilized part of the spine, on the other, needs to be addressed. Combined internal fixation with cemented screws, and the reinforcement of adjacent levels, can help to overcome the troubles related to these osteoporotic spines and allow the surgeon to apply the same technical principles as in healthy bone (Fig. 5).

\section{Surgical techniques}

\section{Vertebroplasty}

Based on the underlying problem polymethylmethacrylate (PMMA) cement is injected percutaneously into the vertebral body(ies) to be treated. This is performed under local anesthesia with an anesthesiologist stand by. Under C-arm control a filling cannula is placed trans- or parapedicularly in the center of the vertebral body. PMMA cement with high radio-opacity and adequate viscosity is injected under continuous control with the image intensifier. This surgical technique is very efficient and allows one to treat up to six vertebral bodies per session, if required [20, 29, 36].

The problem of rectification of lordosis/correction of hyperkyphosis

Vertebroplasty in its proper sense does not allow the rectification of the kyphotic deformity (unless the positioning itself provides some correction Fig. 6); rather, it "freezes it". Thus, kyphoplasty was promoted in order to restore the VB height and was designed to address the kyphotic deformity and help to realign the spine [37, 38]. It involves the percutaneous placement of an inflatable bone tamp into a vertebral body. Restoration of VB height and kyphosis correction is achieved by inflation of the bone tamp with liquid. After deflation a cavity remains that eases the cement application.

Height restoration and decrease of cement leakage are the main points that differentiate this technique from vertebroplasty [39]. The potential of kyphosis reduction gives, in fresh fractures, a range of $0 \%-90 \%$ for height restoration and an absolute correction of the kyphotic angle of 8.5 degrees [40, 41] (Fig. 7). 


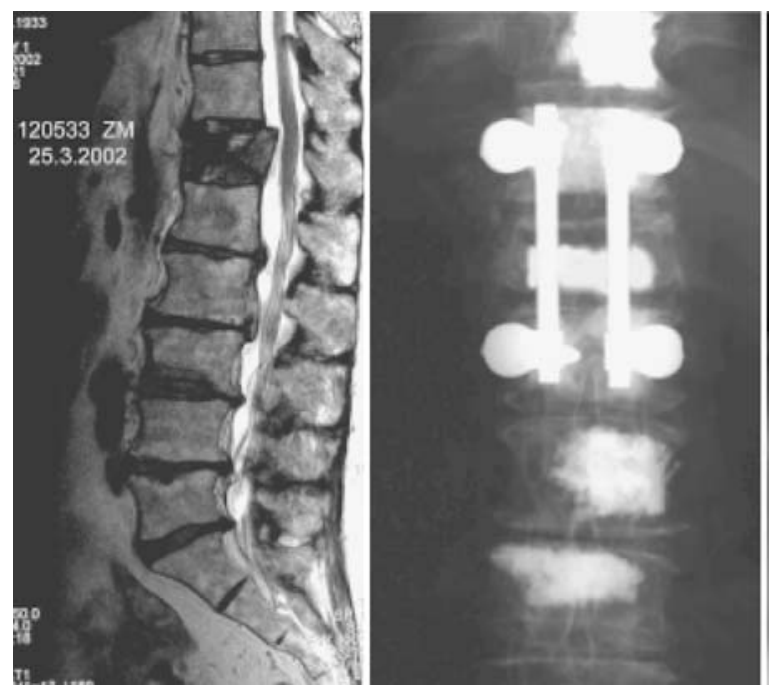

Fig. 5 A 69-year-old woman presented with an unstable fracture of T12. She complained about numbness in both legs when she tried to stand up. In addition there is compression of the lower endplate of L3. There is steroid-induced osteoporosis. The patient suffers from a severe chronic lung disease. The surgical intervention was as limited as possible, with internal fixation of the fractured vertebra and cementing of the adjacent $\mathrm{VB}$

An alternative method for the rectification of lordosis represents the so-called lordoplasty. The vertebral bodies above and below the fracture are equipped with filling cannulas and reinforced by a classical technique. After the cement has cured the cannulas are used as a

Fig. 6a-d Spontaneous rectification of lordosis due to positioning of the patient. The standing X-ray shows a marked kyphotic deformity (a). After positioning, the VB appears nearly completely restored. There is a well-visible cleft in the VB that represents the defect (arrow). The filling pattern of the fractured VB shows the cement distribution along this defect (b). The standing X-ray after the procedure shows a maintained alignment. The adjacent VBs were reinforced as a prophylactic measure (c)
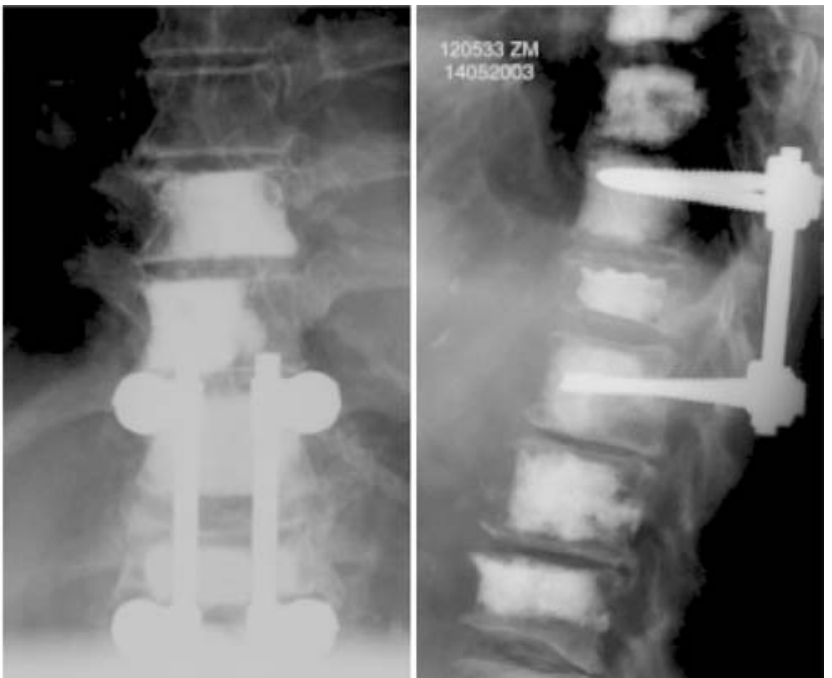

lever, and the collapsed VB is reduced and maintained in this position until cement is injected and has cured. This appears advantageous when compared with the kyphoplasty technique, where we observed a certain loss of the initial reduction after the deflation of the balloons that is a prerequisite before cement can be applied [40] (Fig. 8).

\section{Combined internal fixation and reinforcement}

When internal fixation needs to be performed the reinforcement of vertebral bodies with PMMA enhances the holding power of screws significantly and can help to overcome the otherwise insolvable problem to achieve sufficient stability [42, 43, 44, 45, 46, 47, 48]. The surgical technique follows the standards of pedicle screw insertion. The VB is opened with a pedicle finder and care is taken to achieve a convergent direction without anterior
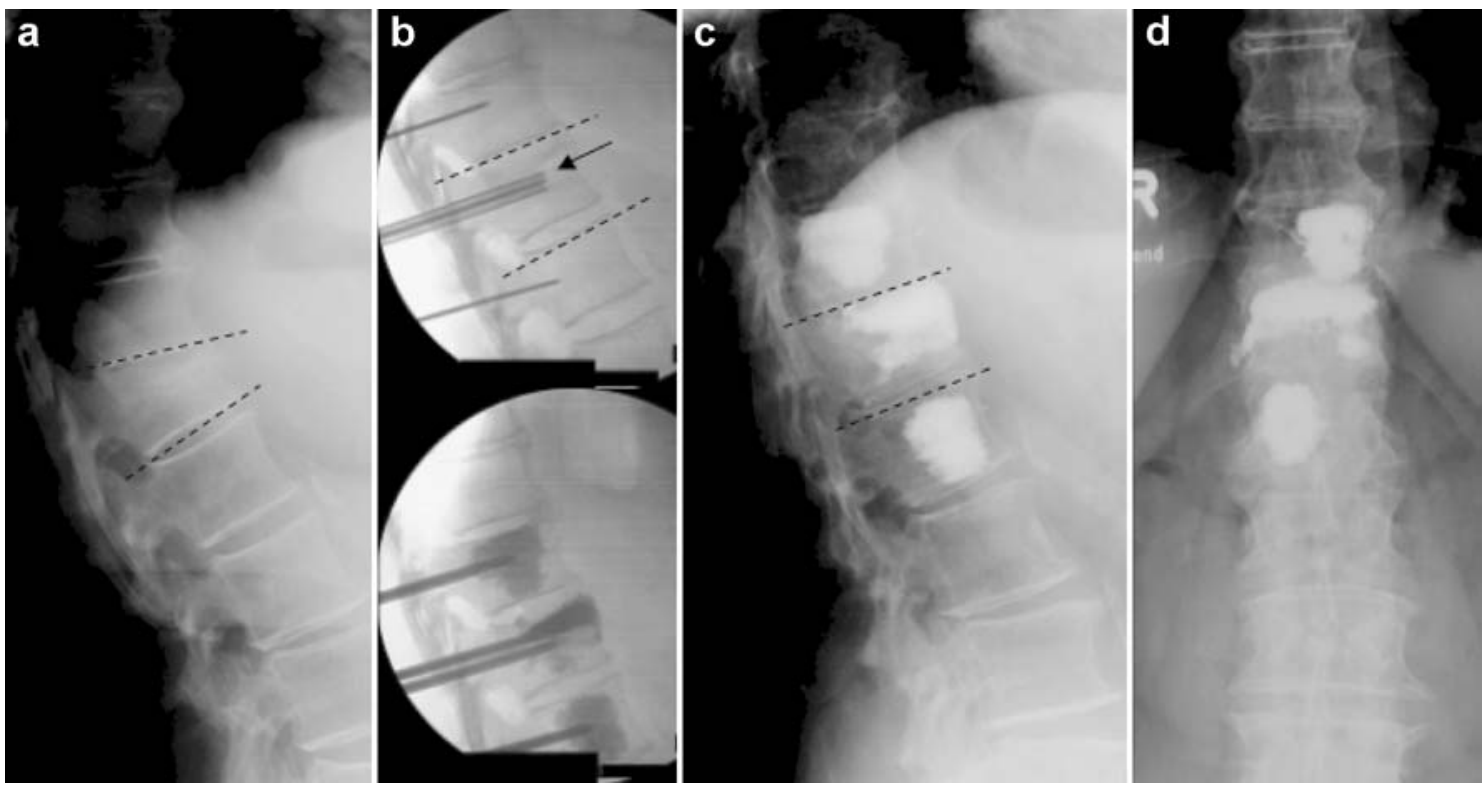

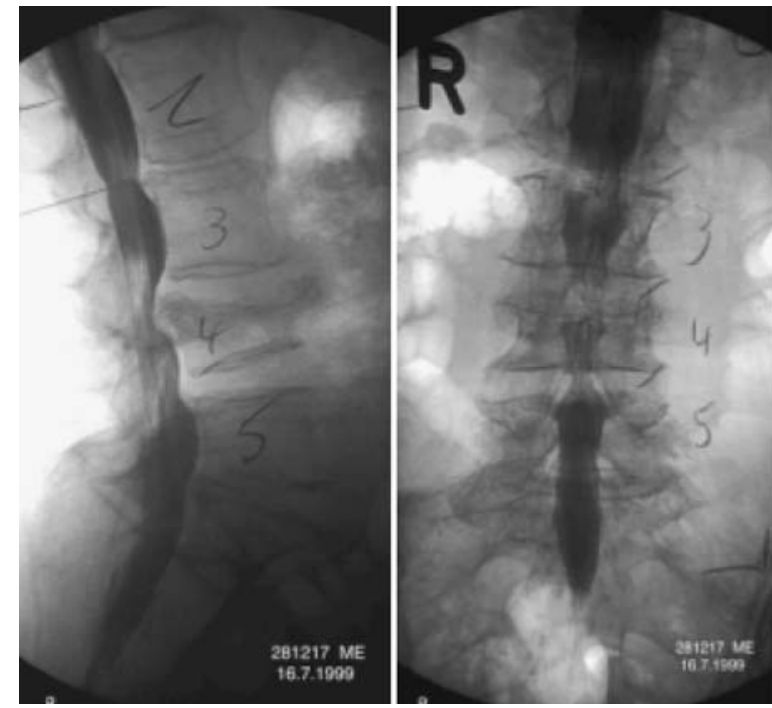

Fig. 7 The potential of height restoration with kyphoplasty: an 82year-old woman with symptomatic spinal stenosis due to a fracture of L4. A kyphoplasty procedure was performed, because of her bad general condition, under local anesthesia. The anterior height of L4 was restored, and, with this, the leg pain disappeared and the patient regained her mobility. Three years after the procedure there has been spontaneous fusion between L3 and L4

penetration of the VB. The VBs are then reinforced as above by the injection of approximately 1.5 to $3 \mathrm{ml}$ of cement on each site. The pedicle screws are inserted before the cement has cured. This is an efficient salving procedure for unsatisfactory stability of implants. Furthermore, the technique allows one to keep the surgical intervention limited, as there is no need to perform long-

Fig. 8 A female patient with localized pain and a VBCF of T9 (a). A follow-up control after 5 weeks depicts a nearly complete collapse of the VB (b). A lordoplasty procedure was performed that allowed significant restoration of the collapsed VB (c). The Fu $\mathrm{X}$-ray shows a well-maintained alignment of the spine (d) distance fixations. Percutaneous reinforcement by the classical technique of vertebroplasty of adjacent vertebra can prevent their collapse.

Our clinical experience with a combination of internal fixation and cement reinforcement includes 21 patients. The main indication represents patients with severe kyphotic deformity due to complete collapse of one or two VBs that undergo an anterior-posterior procedure for spine realignment (Fig. 9). Another important group are patients with spinal stenosis due to an osteoporotic fracture. In these situations the instrumentation is performed by a classical technique, with reinforcement of the VB after decompression has been accomplished. Adjacent vertebrae are reinforced as a prophylactic measure in a second step (Figs. 5 and 9). When longer fixations are performed due to a deformity the key screws are reinforced; they are the most distal and proximal ones and the apex screws.
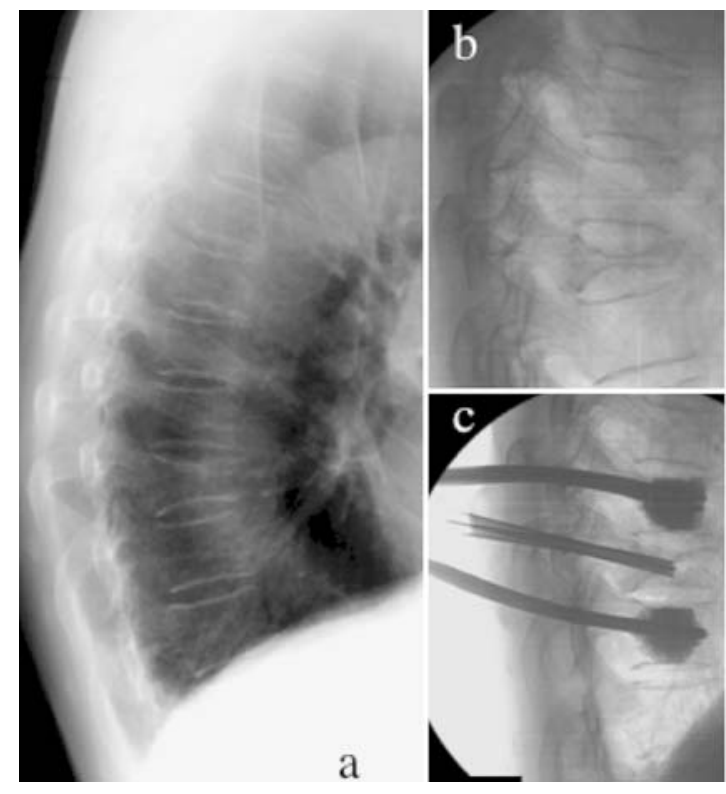

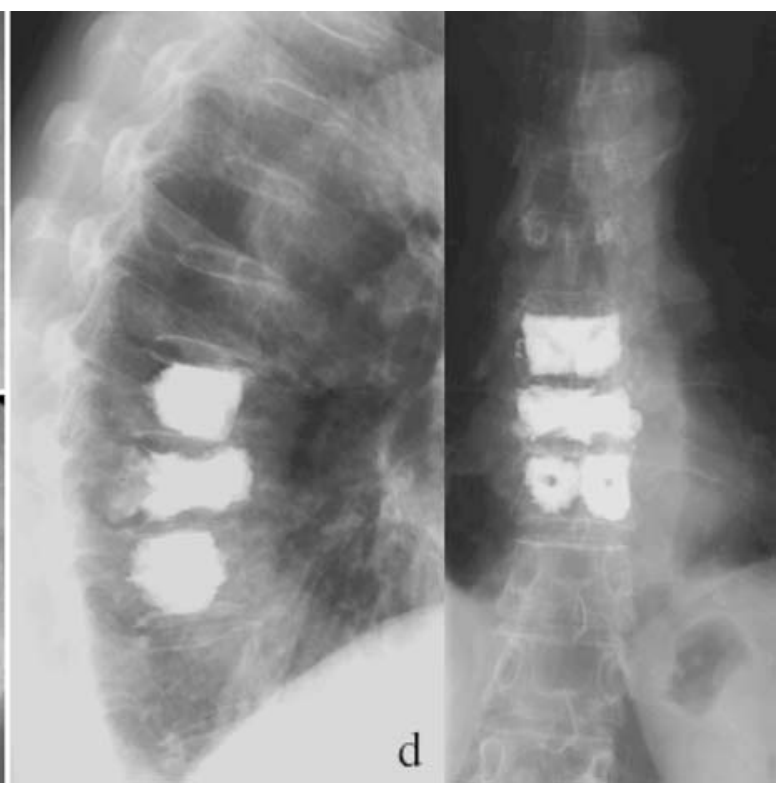



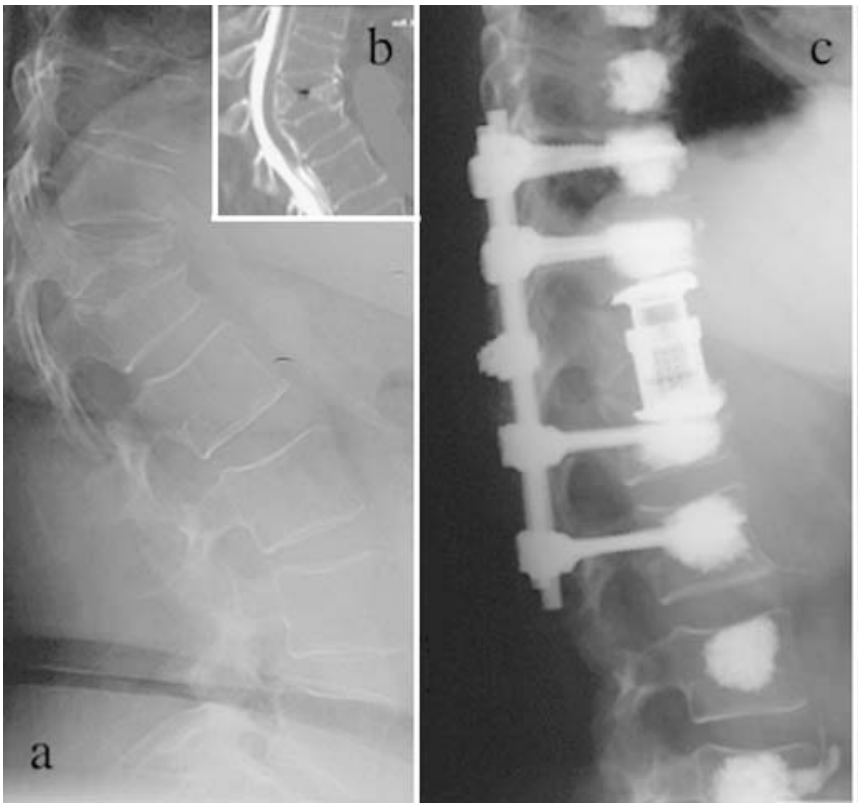

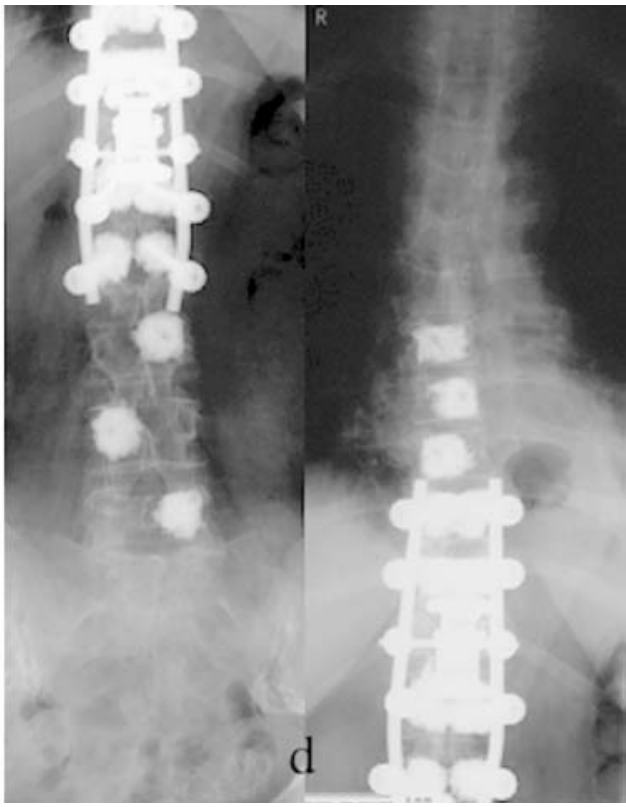

Injection biomechanics will help to improve the surgical technique and increase the safety of the procedure. Pedicle screws adapted for direct cement application can, furthermore, contribute, to facilitate the surgical procedure and improve the surgical outcome. was suffering from severe backache. A combined front-back procedure with anterior release and vertebrectomy of T12 and restoration of the sagittal alignment and posterior stabilization was performed. Because of the poor bone quality, cement was used to increase the anchoring power and avoid subsidence of the cage. In addition the adjacent vertebrae were reinforced, to prevent new fractures. The X-rays 1 year after surgery demonstrate a wellaligned and stable spine $(\mathbf{c}, \mathbf{d})$

\section{Conclusion}

The increasing number of older patients with spine problems that need surgical treatment represents an enormous challenge for the spine surgeon. The oftencompromised general health condition, on one side, and the technical problems related to the osteoporotic bone, on the other side, are a dilemma. The use of PMMA as a means to reinforce bone seems the optimal solution for the problems mentioned.

In painful fractures the injection of the single VB is an excellent means to treat the pain and prevent further collapse. In severe osteoporosis the reinforcement of multiple vertebral bodies can be accomplished, and, if required, the anchorage of implants can be improved with cement, which allow us also to solve the more complex spine problems with less invasiveness and less morbidity for the patient.

Future perspectives. PMMA, as a material, works because of its mechanical and handling properties. Improved mechanical characteristics could help to solve the problem of adjacent level fractures. In younger patients more-bioactive materials, such as injectable $\mathrm{CaP}$ cements, could extend the indication and change the approach of the treatment of vertebral fractures.

\section{References}

1. Melton LJ 3rd, Kan SH, Frye MA, et al (1989) Epidemiology of vertebral fractures in women. Am J Epidemiol 129:1000 1011

2. Silverman SL (1992) The clinical consequences of vertebral compression fracture. Bone 13:S27-31

3. Cooper C, Atkinson EJ, O'Fallon WM, Melton LJ 3rd (1992) Incidence of clinically diagnosed vertebral fractures: a population-based study in Rochester, Minnesota, 1985-1989. J Bone Miner Res 7:221-227

4. Riggs BL, Melton LJ 3rd (1995) The worldwide problem of osteoporosis: insights afforded by epidemiology. Bone 17:505S$511 \mathrm{~S}$

5. EPOS (2002) Incidence of vertebral fracture in Europe: results from the European Prospective Osteoporosis Study (EPOS) J Bone Miner Res 17:716-724

6. Kanis JA, Pitt FA (1992) Epidemiology of osteoporosis. Bone 13:S7-15

7. Lee YL, Yip KM (1996) The osteoporotic spine. Clin Orthop 91-97

8. Ryan PJ, Blake G, Herd R, Fogelman I (1994) A clinical profile of back pain and disability in patients with spinal osteoporosis. Bone 15:27-30

9. Cook DJ, Guyatt GH, Adachi JD, et al (1993) Quality of life issues in women with vertebral fractures due to osteoporosis. Arthritis Rheum 36:750-756

10. Kado DM, Browner WS, Palermo L, et al (1999) Vertebral fractures and mortality in older women: a prospective study. Study of Osteoporotic Fractures Research Group. Arch Intern Med 159:1215-1220

11. Gold DT (1996) The clinical impact of vertebral fractures: quality of life in women with osteoporosis. Bone 18:185S-189S

12. Schlaich C, Minne HW, Bruckner T, et al (1998) Reduced tures. Osteoporos Int 8:261-267 pulmonary function in patients with spinal osteoporotic frac- 
13. Center JR, Nguyen TV, Schneider D, et al (1999) Mortality after all major types of osteoporotic fracture in men and women: an observational study. Lancet 353:878-882

14. Delmas PD (2002) Treatment of postmenopausal osteoporosis. Lancet 359:2018-2026

15. Lindsay R (2001) Risk of new vertebral fracture in the year following a fracture. JAMA 285:320-323

16. Ettinger B, Pressman A, Schein J (1998) Clinic visits and hospital admissions for care of acid-related upper gastrointestinal disorders in women using alendronate for osteoporosis. Am J Manag Care 4:1377-1382

17. Watts NB, Harris ST, Genant HK Treatment of painful osteoporotic vertebral fractures with percutaneous vertebroplasty or kyphoplasty. Osteoporos Int 12:429-437

18. Einhorn TA (2000) Vertebroplasty: an opportunity to do something really good for patients. Spine 25:1051-1052

19. Barr JD, Barr MS, Lemley TJ, McCann RM (2000) Percutaneous vertebroplasty for pain relief and spinal stabilization. Spine 25:923-928

20. Heini PF, Walchli B, Berlemann U (2000) Percutaneous transpedicular vertebroplasty with PMMA: operative technique and early results. A prospective study for the treatment of osteoporotic compression fractures. Eur Spine J 9:445-450

21. Heini P, Orler, R (2004) Vertebroplasty in extreme osteoporosis - experience with multilevel injection. Orthopade (in press)

22. Perez-Higueras A, Alvarez L, Rossi RE, et al (2002) Percutaneous vertebroplasty: long-term clinical and radiological outcome. Neuroradiology 44:950-954

23. Hodler J, Peck D, Gilula LA (2003) Midterm outcome after vertebroplasty: predictive value of technical and patient-related factors. Radiology 227:662-668

24. Maynard AS, Jensen ME, Schweickert PA, et al (2000) Value of bone scan imaging in predicting pain relief from percutaneous vertebroplasty in osteoporotic vertebral fractures. AJNR Am J Neuroradiol 21:1807-1812

25. Kaufmann TJ, Jensen ME, Schweickert PA, et al (2001) Age of fracture and clinical outcomes of percutaneous vertebroplasty. AJNR Am J Neuroradiol 22:1860-1863

26. Brown DB, Gilula LA, Sehgal M, Shimony JS (2004) Treatment of chronic symptomatic vertebral compression fractures with percutaneous vertebroplasty. AJR Am J Roentgenol 182:319-322

27. McKiernan F, Jensen R, Faciszewski T (2003) The dynamic mobility of vertebral compression fractures. J Bone Miner Res 18:24-29

28. Jang JS, Kim DY, Lee SH (2003) Efficacy of percutaneous vertebroplasty in the treatment of intravertebral pseudarthrosis associated with noninfected avascular necrosis of the vertebral body. Spine 28:1588-1592

29. Heini PF, Orler R (2004) Vertebroplasty for severe osteoporosis. Technique and experience with multi-segment injections. Orthopade 33:22-30

30. Heggeness MH (1993) Spine fracture with neurological deficit in osteoporosis. Osteoporos Int 3:215-221
31. Heaney RP (1992) The natural history of vertebral osteoporosis. Is low bone mass an epiphenomenon? Bone 13:S23-26

32. Korovessis P, Maraziotis T, Piperos G, Spyropoulos P (1994) Spontaneous burst fracture of the thoracolumbar spine in osteoporosis associated with neurological impairment: a report of seven cases and review of the literature. Eur Spine J 3:286-288

33. Nguyen HV, Ludwig S, Gelb D (2003) Osteoporotic vertebral burst fractures with neurologic compromise. J Spinal Disord Tech 16:10-19

34. Kim KT, Suk KS, Kim JM, Lee SH (2003) Delayed vertebral collapse with neurological deficits secondary to osteoporosis. Int Orthop 27:65-69

35. Natelson SE (1986) The injudicious laminectomy. Spine 11:966-969

36. Heini PF (2003) Vertebroplasty: the value of prophylactic augmentation. In: Szpalski M, Gunzburg R (eds) Vertebral osteoporotic compression fractures, pp 211-221

37. Wong W, Riley MA, Garfin S (2002) Vertebroplasty/kyphoplasty. J Womens Imaging 2:117-124

38. Garfin SR, Yuan HA, Reiley MA (2001) New technologies in the spine: kyphoplasty and vertebroplasty for the treatment of painful osteoporotic compression fractures. Spine 26:15111515

39. Phillips FM, Todd Wetzel F, Lieberman I, Campbell-Hupp M (2002) An in vivo comparison of the potential for extravertebral cement leak after vertebroplasty and kyphoplasty. Spine 27:2173-2178; discussion 2178-2179

40. Heini PF, Orler R (2004) Kyphoplasty for treatment of osteoporotic vertebral fractures. Eur Spine J 3:184-192

41. Lieberman IH, Dudeney S, Reinhardt MK, Bell G (2001) Initial outcome and efficacy of "kyphoplasty" in the treatment of painful osteoporotic vertebral compression fractures. Spine 26:1631-1638

42. Bai B, Kummer FJ, Spivak J (2001) Augmentation of anterior vertebral body screw fixation by an injectable, biodegradable calcium phosphate bone substitute. Spine 26:2679-2683

43. Jang JS, Lee SH, Rhee CH (2002) Polymethylmethacrylateaugmented screw fixation for stabilization in metastatic spinal tumors. Technical note. J Neurosurg 96:131-134

44. Lotz JC, Hu SS, Chiu DF, et al (1997) Carbonated apatite cement augmentation of pedicle screw fixation in the lumbar spine. Spine 22:2716-2723

45. Wittenberg RH, Lee KS, Shea M, et al (1993) Effect of screw diameter, insertion technique, and bone cement augmentation of pedicular screw fixation strength. Clin Orthop 278-287

46. Moore DC, Maitra RS, Farjo LA, et al (1997) Restoration of pedicle screw fixation with an in situ setting calcium phosphate cement. Spine 22:1696-1705

47. Yerby SA, Toh E, McLain RF (1998) Revision of failed pedicle screws using hydroxyapatite cement. A biomechanical analysis. Spine 23:1657-1661

48. Wuisman PI, Van Dijk M, Staal H, Van Royen BJ (2000) Augmentation of (pedicle) screws with calcium apatite cement in patients with severe progressive osteoporotic spinal deformities: an innovative technique. Eur Spine J 9:528-533 